\title{
DESAFIOS SALINOS PROMOVEM DIFERENTES PERFIS DE EXPRESSÃO MUSCULAR DE HSP70 NOS CRUSTÁCEOS BRAQUIÚROS CALLINECTES DANAE SMITH, 1869 E CALLINECTES ORNATUS ORDWAY, 1863 (OSMORREGULADORES) E HEPATUS PUDIBUNDUS HERBST, 1785 (OSMOCONFORMADOR)
}

\author{
Rios, L.P. ${ }^{1,{ }^{*}} \&$ Freire, C.A. ${ }^{1}$ \\ ${ }^{1}$ Universidade Federal do Paraná (UFPR), Campus Centro Politécnico, Laboratório de Fisiologia Comparativa \\ da Osmorregulação \\ *Autor correspondente: Ipr2012@gmail.com
}

\begin{abstract}
Os braquiúros são caracterizados pela variação na sua morfologia/fisiologia, o que foi essencial na seleção de linhagens que ocuparam os ambientes de águas salobras e água doce. Qualquer que seja o seu habitat/nicho salino, a osmorregulação é essencial para a sua sobrevivência, através da regulação anisosmótica extracelular e/ou da regulação isosmótica intracelular - regulação de volume celular - diante de variações na salinidade da água. Essas alterações de salinidade podem desafiar a atividade normal das células, que por sua vez, ativam respostas de defesa intracelulares, entre elas a possível síntese de chaperonas, como a Hsp70. O objetivo deste trabalho foi avaliar a expressão de Hsp70, em paralelo com o controle da osmolalidade da hemolinfa e da hidratação muscular em 3 espécies de braquiúros: Callinectes danae e Callinectes ornatus (osmorreguladores fracos, marinhos/estuarinos) e Hepatus pudibundus (osmoconformador marinho), diante de desafios salinos. Os animais foram expostos a choque hiposalino (20\%) e hipersalino (45\%), controle (35\%), por 6, 24 e $72 \mathrm{~h}$. Após estes períodos foram retiradas amostras da hemolinfa para análise de osmolalidade, e tecido muscular para determinação do teor de hidratação e análise da expressão de Hsp70. Também foram determinadas a amônia e o pH na água no início e ao final de cada experimento. H. pudibundus apresentou $100 \%$ de mortalidade quando expostos por mais de $6 \mathrm{~h}$ a choque hiposalino, enquanto os espécimes de $C$. danae e C. ornatus sobreviveram ( $0 \%$ mortalidade) a todas as condições. As 3 espécies demonstraram grande capacidade de manutenção da osmolalidade da hemolinfa diante de redução de salinidade, por um período de poucas horas. C. danae e C. ornatus mantiveram a hidratação tecidual inalterada, enquanto $H$. pudibundus perdeu água do tecido muscular a partir de 24 horas de exposição a hipersalinidade. As espécies apresentaram diferentes perfis de resposta na expressão de Hsp70. Enquanto $C$. danae manteve constante a expressão de $\mathrm{Hsp70}$ em todas as salinidades, C. ornatus e H. pudibundus apresentaram, padrões em curva: respectivamente, curva côncava e convexa. A diferença no perfil de resposta pode estar relacionada com a eurihalinidade e padrão de variação de salinidade do ambiente das 3 espécies, e seu grau de regulação anisosmótica extracelular. Alternativamente, C. danae, por ser o mais eurihalino e mais osmorregulador dos 3, pode ter menor necessidade de proteger suas células com investimento na síntese de Hsp70.
\end{abstract}

Palavras-chave: osmorregulação, decapoda, Hsp70. 